\title{
Psychological distress among students from five universities in Sri Lanka
}

\author{
K A L A Kuruppuarachchi', K A J M Kuruppuarachchi', S Wijerathne ${ }^{3}$ and S S Williams
}

(Index words: Rural versus urban and semiurban school education, General Health Questionnaire)

\begin{abstract}
Objective To determine the proportion of university students that are psychologically distressed when compared to an age and sex matched population sample and to describe the factors that may contribute to their distress.

Design A cross-sectional comparison study.

Methods The general health questionnaire (GHQ 30), previously validated in Sinhala, was administered as a screening test to random samples of undergraduates in 5 universities. Age and sex matched controls from the respective communities were also administered the screening test. The undergraduates also filled in a pre-tested questionnaire with personal details. Chi-square tests were used to determine statistical significance between groups.
\end{abstract}

Results Among the undergraduates, 104 (39.8\%) had scores for psychological distress whereas only $67(25.7 \%)$ from the community sample had scores for similar distress. This difference was significant $(\mathrm{p}=0.0007$ ). A significantly greater proportion $(p=0.009)$ of those entering from rural schools were psychologically distressed than those from suburban and urban schools, and a greater proportion living in rented rooms and hostels were $(p=0.001)$ distressed than those travelling from their homes.

Conclusions The psychological distress among undergraduates was significantly greater than among the general population. More students who enter from rural schools seem to be distressed than those who enter from suburban and urban schools.

\section{Introduction}

The recommendations of the Presidential Task Force on university reforms cover key areas such as expansion of university education, curriculum reform, quality assurance, administrative improvements, staff development, career guidance and counselling (1). Entrance to universities is highly competitive as the numbers qualifying for admission far exceed the available vacancies. Between 1996 and 2000 only an average of $16 \%$ of those who qualified for admission were admitted to the universities (2). The entry criteria are based on a dual system: all island merit and merit on a district basis. The district basis seeks to combine merit with equity and fairness, considering the disparities among districts in educational facilities. Allocation to the different universities is also on merit and students who wish to enter the better established univer- sities may be allotted to universities far from their homes. The cost of tertiary education is borne by the State. About 93\% of the students receive financial assistance through Mahapola scholarships or government bursaries (3) that help to cushion their economic burden.

The correlates of stress among university students have been well documented in other countries $(4,5)$. The ability to cope with stress can be a major determinant of students' academic performance and their ability to get the optimum from university years $(5,6)$. Stress can also result in psychiatric morbidity and long term sequels. Sri Lankan universities have a unique cultural, socio-political and economic milieu which warrant a study of their relationship to psychological distress among students.

\section{Methods}

Participants were students in all years of study in the universities of Colombo, Sri Jayawardenepura, Peradeniya and Moratuwa, and the Open University in Colombo. The instrument used as a measure of psychological distress was the Sinhala version of the General Health Questionnaire - GHQ 30 (7) which has been validated in Sri Lanka (Rodrigo EK, personal communication). It has a high validity among students and young people (8). A score of 6 or more on this questionnaire is considered to indicate psychological distress. The undergraduates had also to fill in a pre-tested questionnaire with personal details such as age, sex, marital status, employment, in which school they had their education, course and year of study in university, government economic support for university education, and living arrangements.

Participation in the study was voluntary, informed consent was obtained, and both students and controls selected randomly were guaranteed confidentiality. The results were analysed using the EpiInfo6 statistical package. Chi square tests with Yates correction were used to determine statistical significance.

\section{Results}

The GHQ was administered to 350 university students in the 5 universities of whom 261 (74.6\%) responded. Of those who responded 171 (65.5\%) were men. The age range was 19 to 35 years.

$104(39.8 \%)$ university students had a score of six or more on the GHQ in contrast to $67(25.7 \%)$ in the control

\footnotetext{
'Senior Lecturer, ${ }^{4}$ Lecturer, Department of Psychiatry, Faculty of Medicine, University of Kelaniya, ${ }^{2}$ Educational Assislans, Open University of Sri Lanka and ${ }^{3}$ Medical Officer, District Hospital Anamaduwa. (Received 15 September 2001, revised version accepted 9 Jan 2002. Corresponding author KALAK. Fax +941959337)
} 
population. This difference was highly significant (Table 1). Significantly more male undergraduates had psychological distress than the community sample, whereas among women undergraduates the proportion was not significantly different from that of the community sample. Among the undergraduates, psychological distress was not significantly different between differing age groups, men and women, or those married and single. Among the men $72(42.1 \%)$ had a GHQ score of six or more and among the women $32(35.6 \%)$ had similar scores. Of the $14 \mathrm{stu}$ dents who were married $10(41.7 \%)$ had GHQ scores of six or more and among the singles 94 (39.7\%) had a similar score.

A significantly greater proportion (Table 2) from rural schools had psychological distress than those from suburban and urban schools ( $p=0.009$ ).

The different courses of study and the medium of instruction had no significant effect on psychological dis- tress. A GHQ score of six or more was noted in $38.7 \%$ of those studying in English, $35.2 \%$ studying in Sinhala, and $44.6 \%$ of those following a course which used both languages. There was also no significant difference in psychological distress among the students in different years of study or in the different universities.

Neither the type of economic support the student received nor whether they were employed, seemed to play a significant role. Of the $43(16.5 \%)$ students who were employed 12 (27.9\%) had a GHQ score of six or more. Of the 218 who were unemployed, $92(42.2 \%)$ had a GHQ score of 6 or more. Of those receiving Mahapola grants 28 (48.3\%) had GHQ scores for psychological distress while of those who had to depend on their parents 64 (39.3\%) had similar scores. Those who travel from home had significantly less psychological distress than those who stay in university hostels or in rented rooms $(\mathrm{p}=0.001)$ (Table 2).

Table 1. Comparison of psychological distress (GHQ score $\mathbf{2} 6$ ) among the university sample and the control sample

$\begin{array}{lccc} & \begin{array}{c}\text { University sample }(\%) \\ (n=261)\end{array} & \begin{array}{c}\text { Control sample }(\%) \\ (n=261)\end{array} & p \text { value } \\ \text { Males } & 72(42.1) & 43(25.1) & \\ \text { Females } & 32(35.6) & 24(26.7) & 0.001 \\ \text { Total } & 104(39.8) & 67(25.7) & 0.259 \\ & & \end{array}$

(GHQ - General Health Questionnaire)

Table 2. Comparison of psychological distress in relation to school attended and the type of accommodation of university students

Number responding Number distressed $\quad$ Distressed \%

School attended

$\begin{array}{lrrr}\text { Rural } & 26 & 17 & 65.4 \\ \text { Suburban } & 99 & 36 & 36.4 \\ \text { Urban } & 136 & 51 & 37.5\end{array}$

\section{Accommodation}

Travelling from home

In university hostel 


\section{Discussion}

This study shows that there is significant psychological distress among university students when compared to age and sex matched controls in the community. More male undergraduates are distressed than their counterparts in the community. The distress is greater in those living away from home in rented rooms and in university hostels, and those who have entered the university from rural schools. The limitations of the study are that all the universities included are in urban or semi-urban surroundings in and around Colobmo and in Peradeniya, whereas the universities in the provinces and the universities in the war-torn north and east have been excluded form the study. As shown in other studies (9) gender did not show up as a factor for added stress within the university student popuiation.

No difference in psychological distress was evident among students following different courses of study. This may be due to the fact that students following more strenuous courses such as medicine or engineering are usually assured of a job with a higher earning capacity at the end it, in contrast to those following an arts or science course, who have uncertainties ragarding future employment (11). Furthermore, a greater percentage of arts students come from lower economic backgrounds than those following profesşional courses (11).

The greater proportion of psychological distress among students entering from rural schools needs attention. Entering university involves adjustment at various levels. They have to cope with a new unfamiliar environment that is vastly different from the rural setting while adjusting to the stress of the course itself. These factors have been clearly demonstrated in the causation of psychological distress (5). The excess of students from rural schools who have psychological distress may be related also to the differences observed between students who travel to unversity from their homes and those who do so from rented rooms and university hostels away from home.

\section{References}

1. Presidential Task Force on University Education Reforms. Colomob, 1998.

2. University Statistics 2000 . University Grants Commission, Sri Lanka, 2000.

3. Review of University System. Sri Lanka Universities Year Book 1997/98. University Grants Commission, Sri Lanka, 1998; 1: 3-4.

4. Ko SM, Kua EH, Fones CS. Stress and the undergraduates. Singapore Medical Joumal 1999; 40: 627-30.

5. Schreier AR, Abramovitch H. American medical students in Isreal: Stress and coping. Medical Education 1996; 30: 445-52.

6. Stewart SM, Lam TH, Betson CL, Wong CM, Wong AMP. A prospective analysis of stress and academic performance in the first two years of medical school. Medical Education 1999; 33: 243-50.

7. Goldberg D. Manual of the General Health Questionnaire. Windsor National Foundation for Educational Research, 1978.

8. Radanovic Z, Eric LJ. Validity of the General Health Questionnaire in a Yugoslav student population. Psychological Medicine 1983; 13: 205-7.

9. Guthrie EA, Black D, Shaw CM, Hamilton J, Creed FH et al. Embarking upon a medical career; psychological morbidity in first year medical students. Medical Education 1995; 29: 337-41.

10. De Silva NR, Thabrew MI, Saparamadu PAM, Jayawardena DKRC, Arachchige AA et al. Gender differences in undergraduate medical examination results in Sri Lanka. Ceylon Medical Journal 2000; 45: 119-22.

11. Sanyal BC, Diyasena W, Gunatilleke G, Wijemanne EL, Bastianpillai B et al. University education and graduate employment in Sri Lanka. The Marga Institute - Unesco 1983; 180: $199-202$. 